\title{
A New Exobasidium-Disease
}

\author{
of \\ the Tea-Plant.
}

by

S. Ito. and K. Sawada.

In May of the last year, one of the authors received a diseased specimen of the tea plant (Thea sinensis L.) from $\mathrm{Mr}$. T. Hanzawa, who had collected it in Prov. Suruga. He and Mr. M. KajI kindly informed us, that it is one of the most serious enemies of the tea planters throughout the province, and that it appears early in season when the tea-leaves are just unfolding. They also wrote that the loss on the first picking due to this disease was estimated at about $20 \%$ in the districts of Abe and Ihara. Some tea plantations in the same districts were affected with this disease to such an extent, that hardly any young leaf is completely free from the diseased spots.

During the course of the mycological study of Formosa, another author observed also the present disease, which is a very common trouble in the tea districts of northern Formosa. The leaves of the tea plant affected with the disease were noticed from the latter part of January, and the disease often causes a great damage almost as much as the blister-blight.

Under the microscope, we may easily recognise the causal fungus of the disease to be a species of Exobasidium, but the symptoms as well as the nature of the fungus differ from those of the well known blister-blight of the same plant, caused by Exobasidium vexans MAssee, in many respects.

These two places, Suruga and Formosa, are widely separated, yet the disease in question seems to have not yet been collected from any of the intervening tea districts. But in the 
near future, we are sure the disease will certainly be observed in the various localities of our country.

The first indication of this disease is a small, pale yellow speck on the surface of the leaf, and we can see the darker netted lines in the tissue of the spot on the affected young leaf, when it is held up against the sun. The speck on a single leaf is variable in number, mostly one or two. It is not clearly limited in outline, irregular in shape, gradually enlarging until it reaches a diameter of 2 or $3 \mathrm{~cm}$., but sometimes until it covers the entire leaf surface. The color of the speck gradually turns into brown and finally into dark brown. The corresponding surface on the under side of the leaf assumes at first a gray, dusty appearance. As they mature, the darker reticulated lines in the tissue are at first slightly raised above the level of the leaf-surface, and then by breaking through the epidermis, the characteristic white reticulated hymenium of the fungus is exposed. (Fig. 1)

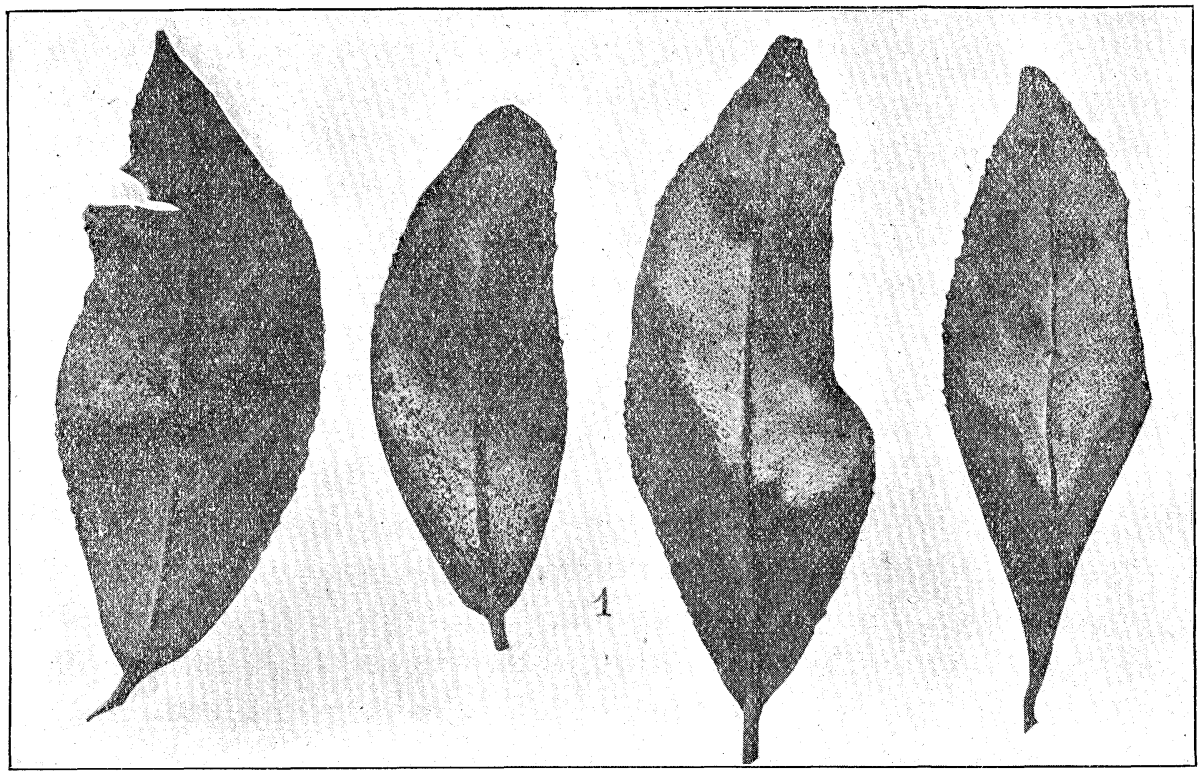

The hymenium turns gradually into dark brown color from the central portion toward the periphery of the speck. Finally, the affected area of the leaf becomes dry and shrinks up. 
A section through the diseased spot shows the hyphae to be ramifying in the tissue of the leaf and the chloroplastids destroyed. The hymenium is about $70-90 \mu$ in thickness. (Fig. 2.) The basidia are cylindrical clavate in shape, and usually produce four sterigmata on the apex. The basidia measure 100-135 $\mu$ $\times 3-4 \mu$; and the sterigmata $2-3 \mu$ in length. Each sterigma supports a basidiospore. (Fig. 3, 4.) The basidiospores are oblong-obovate in shape, straight or more or less curved, hyaline, granulate and they measure $9-12 \mu \times 3-3.5 \mu$. (Fig. 5.) Besides these one-celled spores, two-celled spores are often observed on the same hymenium. They are slightly larger than the former, and similar in shape and color, not or slightly constricted at the septum, and they are often found germinating in situ. (Fig. 6, 7.)

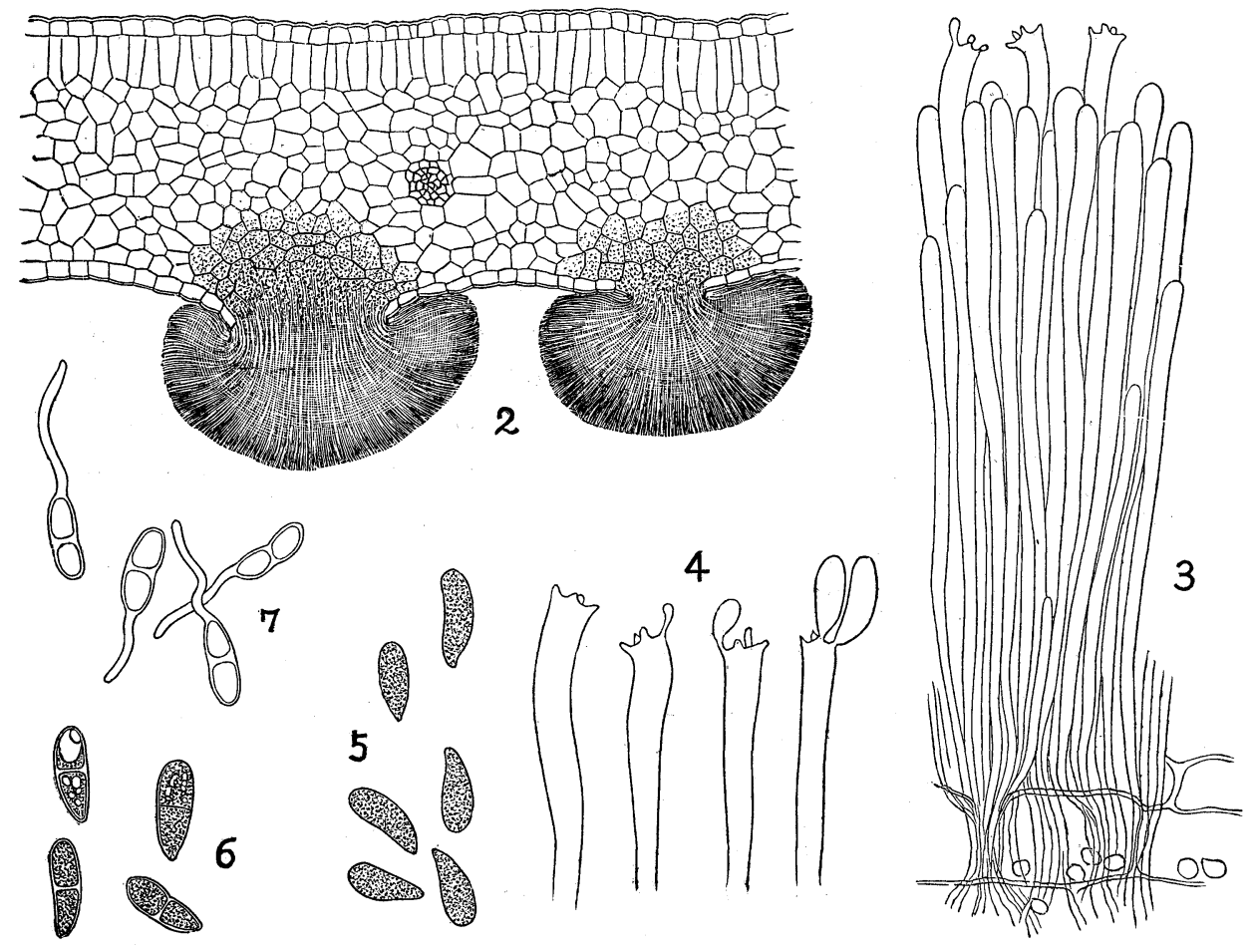

In the case of Exobasidium vexans, such two-celled spores also have been observed ; but they were recognised as "conidia" 
by MASSEE* and many other authors. ${ }^{* *}$. It is a remarkable and interesting fact, if MASSEE's view be correct, that the fungus belonging to Exobasidium produces such a conidium in its life cycle. On the other hand, the basidiospores of Exobasidium seem to be generally recognised to produce a septum in the process of their germination. From these points, the further experiments are required to decide the nature of these two-celled spores. In the case of the present fungus, the two-celled spores may only be observed in an old hymenium, and almost always they are found germinating, but they could not be obtained from a young specimen. From these facts, we may be justified in considering the two-celled spores as a mere stage of the basidiospores-at least in the case of our fungus.

Let us then briefly state on the differences between the present disease and the related "blister-blight."

In the macroscopical appearance they differ strikingly from each other. The spot of the blister-blight is more or less regular, roundish, clearly limited, and pale yellow, but sometimes becomes colored deep red on both sides. The circular spot generally reaches to the size of $15 \mathrm{~mm}$. in diam., sometimes as much as $23 \mathrm{~mm}$; it becomes gradually depressed into a shallow cavity; when matured, it gives eventually a white powdery appearance on the entire convex under-surface. On the other hand, the spot of the disease in question, as already stated, is irregular in shape, not limited, and never reddish in color; and moreover it becomes never bullated and forms a white reticulation on the under surface.

Microscopically these two species differ from each other in the measurement of therr various parts, as follows :-

$\begin{array}{lcc} & \text { Exob. vexans. } & \text { Exob. sp. } \\ \text { Basidia } & 49-150 \times 3.5-6 \mu & 100-135 \times 3-4 \mu \\ \text { Sterigmata } & 3-4.5 \mu & 2-3 \mu \\ \text { Basidiospores } & 11-16 \times 4-6 \mu & 9-12 \times 3-3.5 \mu\end{array}$

Besides these facts, these two species differ from each other in the number of sterigmata on a basidium.

While the sterig-

* "Tea Blights," New Gardens Bulletin. 1898.

** Watt, Mann, Speschnew and Mc Rae. 
mata on a basidium of the blister-blight fungus are generally two in number, those of the present fungus are invariably four.

From the foregoing statements made on the distinctness of our fungus from its related species, we considered it as a new species. The diagnosis of this fungus, for which we propose the name Exobasidium reticulatum is as follows :-

\section{Exobasidium reticulatum S. Ito et Sawada.}

Spots, on leaf, mostly one or two in number, scattered, not limited, 2 or $3 \mathrm{~cm}$. in diam., sometimes covering the entire surface, yellowish then brown to dark brown in color, at last becoming dry and shrink up. Hymenium hypophyllous, reticulated, white ; basidia cylindrical clavate, hyaline, 100-135 $\times 3-4 \mu$; sterigmata on a basidium are 4 in number, $2-3 \mu$ in length. Basidiospores oblong-obovate, straight or slightly curved, hyaline, continuous, granulate, 9-12 $\times 3-3.5 \mu$. Twocelled basidiospores oblong-obovate, hyaline, not or slightly constricted at the septum, often with germ-tubes.

Hab. On leaves of Thea sinensis L.

Honshu:- Prov. Suruga. May 1911. T. Hanzawa.

Formosa :- Taihoku. Nov. 16, 1908 ; Jan. 27, 1910; April 18,

1911. K. SaWAda.

In conclusion, we wish to express here our heartiest thanks to Prof. Dr. K. Mivabe to whom we are indebted for his many valuable suggestions.

June 1912.

In the Phytopathological Laboratry, College of Agriculture, Tōhoku Imperial University, Sapporo, Japan. 